\title{
Bcl-2, an Antiapoptotic Gene Indicator of Good Prognosis in Breast Cancer: The Paradox
}

\section{Maximino Redondo*}

Department of Biochemistry, Hospital Costa del Sol, University of Málaga, REDISSEC, Carretera de Cádiz km 187, 29600, Marbella, Málaga, Spain

Breast cancer is the most frequently diagnosed cancer among women. Alterations in different genes are involved in the development of this tumour [1] and alterations in crucial pathways related to proliferation and apoptosis have been used as targets for treatment [2]. Bcl-2 protein is a member of the bcl-2 family that regulates apoptosis. The bcl-2 gene encodes a MR 26000 protein that is mainly localized in the mitochondrial membrane and, to a lesser extent, in the nuclear membrane and the endoplasmic reticulum. Its implication in carcinogenesis and progression makes this gene worthy of investigation. Its tumourigenic potential has been demonstrated: bcl-2 protein blocks apoptosis and cooperates with c-myc in cell transformation [3]. In addition, in the MCF-7 breast cancer cell line the overexpression of bcl-2 enhances both tumourigenicity and metastatic potential [4]. However, in many solid organ tumours, including breast cancer, bcl2 expression, paradoxically, is associated with favourable prognostic features and good outcome [5,6]. Interestingly, the expression of bcl2 is higher in screen-detected cancers than in symptomatic cancers [7] and, in a recent report, bcl-2 expression was shown to be lower in the stroma of precancerous fibroadenoma lesions than in those of non-cancerous lesions [8]. In their metaanalyses, Dawson et al. [6] supported the prognostic role of bcl-2 in breast cancer, as assessed by immunochemistry, and showed that this effect is independent of other variables.

The mechanisms through which bcl-2 might exert its protective effect in breast cancer are unclear. Thus, it has not been determined whether bcl-2 is involved directly in contributing to this more indolent phenotype or is simply an epiphenomenon that is a marker for another molecular or biologic process. The anti-apoptotic role of bcl-2 is well characterised but its function in cell cycle control has received less attention. Cell line studies have shown that bcl-2 exerts growth inhibitory effects by prolonging G0 and G1 progression [9], and it has been postulated that the dominance of one of these functions over another may depend on the cell type. Therefore, as bcl-2 does not promote cell proliferation, in the absence of additional genetic alteration, bcl-2 positive tumours tend to be relatively non-aggressive. Furthermore, it should be considered that other components of the apoptotic pathway might also play an important role. It is well recognized that apoptosis regulation is very complex and that bcl2 is only one member of a family of genes, each with different roles in the regulation of cell death. The mechanisms by which the interactions between the various members of the bcl-2 family finally lead to apoptosis are still unknown. On the other hand, it could be hypothesized that the favourable clinical outcome of patients with high bcl-2 expressing tumours could be better explained by a relationship between bcl- 2 expression and differentiation than by the role played by the proto-oncogene in the apoptosis process. In this sense, the presence of bcl-2 immunostaining in normal tissue and its persistence in tumour tissue could indicate a predisposition to differentiation. However, in some series the expression of bcl-2 shows no statistical relationship with differentiation $[5,10]$. On the other hand, gene-transfer-mediated elevations in bcl-2 protein have been shown to protect tumour cells from cell death induced by radiation and a wide range of anticancer drugs in hematologic malignancies [11]. The down-regulation of bcl-2 during anti-oestrogen treatment would probably produce a favourable response to this therapy. However, significantly longer survival times, irrespective of the type of adjuvant therapy, have been reported [6]. Clearly, therefore, the prognostic power of bcl-2 as a single marker in breast cancer has been demonstrated, but the therapeutic implication of these findings and the question of how bcl-2 might improve the selection of patients for treatment remains to be determined. Accordingly, large-scale studies including clinical trials are needed to confirm its clinical utility.

\section{References}

1. Naga-Anusha $P$ (2011) Epidemiology of genetic alterations in progression of breast cancer. J Carcinogene Mutagene 2: 125.

2. Bareggi Renato NV, Paola N (2010) New targeted therapies against breast cancer. J Carcinogene Mutagene 1:110

3. McDonnell TJ, Korsmeyer SJ (1991) Progression from lymphoid hyperplasia to high-grade malignant lymphoma in mice transgenic for the $t(14 ; 18)$. Nature 349: 254-256.

4. Del Bufalo D, Biroccio A, Leonetti C, Zupi G (1997) Bcl-2 overexpression enhances the metastatic potential of a human breast cancer line. FASEB $J$ 11: $947-953$

5. Villar E, Redondo M, Rodrigo I, García J, Avila E, et al. (2001) bcl-2 Expression and apoptosis in primary and metastatic breast carcinomas. Tumour Biol 22 137-145.

6. Dawson SJ, Makretsov N, Blows FM, Driver KE, Provenzano E, et al. (2010) BCL2 in breast cancer: a favourable prognostic marker across molecular subtypes and independent of adjuvant therapy received. $\mathrm{Br} J$ Cancer 103: 668675

7. Redondo M, Funez R, Medina-Cano F, Rodrigo I, Acebal M, et al. (2012) Detection methods predict differences in biology and survival in breast cancer patients. BMC Cancer 12: 604.

8. Kathan R, Senger JL, Kanthan SC (2011) Stromal signatures of breast carcinogenesis in fibroadenoma-A pilot study. J Carcinogene Mutagene 2:123.

9. Pietenpol JA, Papadopoulos N, Markowitz S, Willson JK, Kinzler KW, et al. (1994) Paradoxical inhibition of solid tumor cell growth by bcl2. Cancer Res 54: $3714-3717$

10. Leek RD, Kaklamanis L, Pezzella F, Gatter KC, Harris AL (1994) bcl-2 in

*Corresponding author: Maximino Redondo, Department of Biochemistry, Hospital Costa del Sol, University of Málaga, REDISSEC, Carretera de Cádiz km 187, 29600, Marbella, Málaga, Spain, E-mail: mailto:mredondo@hcs.es

Received January 21, 2013; Accepted January 22, 2013; Published February 05, 2013

Citation: Redondo M (2013) Bcl-2, an Antiapoptotic Gene Indicator of Good Prognosis in Breast Cancer: The Paradox. J Carcinogene Mutagene 4: 134 doi:10.4172/2157-2518.1000134

Copyright: (c) 2013 Redondo M. This is an open-access article distributed under the terms of the Creative Commons Attribution License, which permits unrestricted use, distribution, and reproduction in any medium, provided the original author and source are credited. 
Citation: Redondo M (2013) Bcl-2, an Antiapoptotic Gene Indicator of Good Prognosis in Breast Cancer: The Paradox. J Carcinogene Mutagene 4: 134. doi:10.4172/2157-2518.1000134

Page 2 of 2

normal human breast and carcinoma, association with oestrogen receptorpositive, epidermal growth factor receptor-negative tumours and in situ cancer. Br J Cancer 69: 135-139.
11. Reed JC, Kitada S, Takayama S, Miyashita T (1994) Regulation of chemoresistance by the bcl-2 oncoprotein in non-Hodgkin's lymphoma and lymphocytic leukemia cell lines. Ann Oncol 5 (suppl 1): S61-S65. 